\title{
SUBJECTIVE WELL-BEING, POVERTY AND ETHNICITY IN SOUTH AFRICA: INSIGHTS FROM AN EXPLORATORY ANALYSIS*
}

(Accepted 12 December 2005)

\begin{abstract}
South Africa has one of the highest inequality levels in the world. In 1993, nearly half of the population were considered poor. These poverty and inequality levels were and still are a legacy of South Africa's colonial and apartheid past. Since the end of apartheid, there has been a strong governmental effort to combat poverty and in this light a 'social indicators movement' has emerged. The aim of this article is to contribute to the South African social indicators research in three ways: Firstly, this article introduces ethnicity as a unit of analysis in the context of poverty and well-being. It is argued that racial categorisations are not justifiable and in the case of South Africa hide valuable insights. The results of an exploratory analysis suggest that ethnicity allows a more insightful analysis of poverty and well-being than race. Secondly, this article introduces a multiple correspondence analysis (MCA) in the context of subjective well-being research. Many studies regarding subjective well-being in South Africa use ordered probit regression models. It is argued here that these models are based on false assumptions and that a MCA can be seen as a suitable alternative since it constitutes an assumption free model. Lastly, the insights gained from the exploratory analysis are discussed. The MCA seems to show that subjective well-being can be regarded as an outcome measure. Furthermore, it is argued that there are cultural differences (between the ethnic groups) regarding subjective well-being. It seems that the ethnic groups in South Africa have different conceptions of well-being and that different factors influence their subjective well-being assessments.
\end{abstract}

KEY WORDS: multiple correspondence analysis, poverty, South Africa, subjective well-being

\section{INTRODUCTION}

In international comparisons South Africa is ranked by the World Bank as an upper-middle-income country (World Bank, 2005) ${ }^{1}$. However it is estimated that South Africa has one of the highest inequality levels in the world.

*This work is partly based on a Master thesis from 2004 at the Institute for Development Policy and Management at the University of Manchester. I am grateful for the intellectual guidance, the constant support and encouragement by Wendy Olsen and for the comments on earlier drafts from Peter Edward, David A. Clark and two anonymous reviewers. 
Indications in 1993 were that approximately half of the population could be considered poor, receiving together just $11 \%$ of South Africa's total annual income, whereas the richest $7 \%$ of the population received over $40 \%$ of the country's income $^{2}$ (May et al., 2000; SAHDR, 2003). Although during the early 1990's apartheid was brought to an end, this high level of inequality is still persistent and must be seen as a legacy of South Africa's colonial and apartheid past (see Ross, 1999; Glaser, 2001; Aliber 2003) .

After the end of apartheid, the newly elected democratic South African government planned to combat poverty. Therefore accurate information about the extent and severity of poverty was needed. During apartheid rule official statistics did not cover the whole of South Africa and did not produce representative household surveys, so no accurate picture of poverty existed until 1993/1994. For example, four of the poorest so-called 'homelands' were excluded where approximately $20 \%$ of South Africa's population and $30 \%$ of the poor live had been living (Klasen, 1997). This study is based on the first nationally representative household income and living standards survey of South Africa (see Carter and May, 1999) which covered all South African communities (PSLSD, 1994). ${ }^{4}$

Since the political change to democracy there has been an increase of quantitative surveys, and a growing number of scholars are researching social indicators for South Africa in what Møller (1997, p. 1) terms a 'social indicators movement'. This paper tries to contribute to the social indicators debate by firstly arguing that language might be an important basis for understanding the diverse nature of South Africa's population. It is suggested that race, as a widely used unit of analysis in quantitative social science, is imperfect and that ethnicity needs to be broken down further before it can be useful. In this study it will be pointed out that combining language with the existing racial categories can be a better basis for understanding the diversity among the racial groups. This ethnic breakdown helps to understand inter-ethnic differences in poverty or well-being. Furthermore, this study proposes an exploratory analysis technique for ordinal data called multiple correspondence analysis which is seen as a useful alternative to regression models. This technique allows one to explore the inter-ethnic differences in poverty or well-being.

\subsection{Aim of Research}

The aim of this research is twofold. Firstly, looking at the case of South Africa, this paper explores the extent to which an ethnic classification could represent a better alternative unit of analysis than race, especially regarding 
poverty or inequality analysis. Research suggests (e.g. Stanfield, 1993) that racial categorisations are not justifiable since racial groups do not form homogeneous groups. Lester et al. (2000) argue that in South Africa (as well as in other countries), social and political power was used to artificially construct and reconstruct 'race'. They point to the example of the practice of annual reclassifications during the apartheid period, where each year hundreds of individuals successfully applied to be reclassified to a different distinct social (racial) group. Due to this constructed nature of race, ethnicity will be used as a unit of analysis derived from the combination of race and language which is regarded as a more valid categorisation. It will then compare how these ethnic groupings perform with respect to poverty and well-being (namely expenditure poverty, capability poverty and subjective well-being) vis-à-vis the racial categorisation ${ }^{5}$. Are there differences in poverty levels between the racial groups (inter-racial), or inside the racial groups (intra-racial), and are they differentiated according to ethnicity? This question will be explored with the use of simple mean scores of these three poverty measures. Secondly, this paper introduces a multiple correspondence analysis, arguing that it is a suitable alternative to common analysis techniques (i.e. ordered probit regression) since it is not based on weak model assumptions. With the help of this technique it will be argued that apart from intra-racial differences, intra-ethnic differences also exist. Lastly, the findings of the exploratory analysis are discussed and the insights gained in respect to existing research are summarised.

\section{POVERTY/WELL-BEING MEASURES}

The measures selected for this study are two poverty measures (monetary poverty and capability poverty) and one subjective well-being measure (life satisfaction). Monetary well-being is based on the idea that someone has command over adequate income to meet minimal consumption requirements for human welfare, whereas the capability approach views poverty as a function of the lack of individual capabilities to achieve a basic level of human well-being (Wagle, 2002). Subjective well-being reflects the cognitive evaluation of one's life and is therefore to be regarded as the broadest concept, since it is not restricted to just one dimension (income or expenditure - as in the monetary approach) or several dimensions (like health, education and income - as in the capability approach) but is open to all the dimensions the individual is incorporating for its evaluation. The terms 
poverty and well-being are used interchangeably, in the sense that it is assumed that the absence of poverty constitutes well-being.

\subsection{Monetary Poverty}

Monetary approaches represent the most widely used poverty measures and have been pioneered by economists. In general, economists perceive poverty as a lack of resources relative to needs, whereby it is assumed that consumption or income are good proxies for needed consumables like food or clothing. Economists value this approach because it is compatible with the utility maximising behaviour assumption which represents the foundation of microeconomics. It is widely assumed that the utility maximising behaviour is reflected in expenditure which in turn reflects the marginal value or utility people place on commodities (Ruggeri Laderchi et al., 2003). The basic premise the monetary approach rests on is that uniform monetary metrics can take into account the relevant heterogeneity across individuals and their situations. Therefore one single indicator like income or consumption is believed to be sufficient to measure individual well-being. Poverty is therefore identified as a shortfall of income or expenditure from some pre-defined poverty line. These poverty lines are distinguished according to whether they are 'relative' or 'absolute'.

Relative deprivation has to be understood as the poverty of individuals relative to others in the society in which they function. In other words, whether or not one is poor depends not only on individual (or household) income/consumption, but also on the income/consumption of others in society. Therefore a person is regarded as poor, for instance, if his or her income or consumption level is below a particular fraction of the national average. The basic concept that the relative approach is based on is that societies and living standards are constantly changing and, therefore poverty lines also need to change accordingly (Wagle, 2002). Further it is assumed that societies differ and therefore a single absolute poverty line cannot be applied for all societies but has to be relative to the living standards of that particular society. Nevertheless relative poverty approaches cannot avoid defining a poverty line, which is expressed as a certain percentage of the median or mean income or expenditure level of the social reference group. Compared to the median, the mean is regarded as imperfect, because changes of income of the richest persons affect the poverty line, whereas the median stays unaffected. Although a consensus is lacking, relative poverty thresholds are usually set at either 40,50 , or $60 \%$ of mean or median income (Jesuit and Smeeding, 2002). In general, relative poverty measures are 
criticised for not reflecting the well-being of those who are poor. It is argued that a person might be relatively poor but this is not necessarily mean that he or she is absolutely poor. For example there might be an improvement in relative poverty while absolute poverty is increasing or vice versa. Another problem with the relative poverty concept is that it is not clear what an improvement in relative poverty indicates (Blackwood and Lynch, 1993). Therefore the application of a relative poverty line in a time-series study might be limited.

In contrast, absolute poverty has to be understood as the deprivation of individuals relative to some predetermined poverty line which is for example defined as a market-priced basket of goods and services comprising the basic commodities essential to meet one's own or one's family's basic or minimum requirements which are proxied through income or consumption. The inherent problem of defining basic means of survival is that this always involves arbitrary standards due to the fact that the issue of survival is immediately related to the quality of survival (Wagle, 2002). For example, basic means could be defined in a way that an individual is able to survive in a medical sense, but that might imply that his quality of life is severely restricted. Despite this problem, poverty has been defined in terms of some survival criteria, expressed in a poverty line. This poverty threshold implies that there is some form of difference between the poor and the non-poor which can be represented through a poverty line.

Recent research in chronic poverty suggests that the poor are not a homogenous group and therefore differentiate between 'always poor', 'usually poor', 'fluctuating poor', 'occasionally poor' and 'non-poor' (see Hulme et al., 2001; Hulme and Shepherd, 2003; CPRC, 2004). Although chronic poverty is normally measured using the income and time space, scholars acknowledge that poverty 'has breadth', i.e. that poverty is multidimensional (Clark and Hulme, 2005, p. 3). One such multidimensional but purely theoretical - approach is the so-called capability approach.

\subsection{Capability Poverty}

The capabilities approach was introduced in the late 1970s and advanced in a series of journal papers and books by Amartya Sen $(1981,1990,1999)$ and constitutes a comprehensive framework for conceptualising human well-being and development, which is rooted in a critique of the ethical foundations of utilitarianism (Ruggeri Laderchi et al., 2003). Sen's critique addresses the basic assumptions of rational choice or utility theory that 
equates rational behaviour with self-interested utility maximisation. Based on this critique Sen developed a theoretical framework that is grounded in the idea that market outcomes should be judged in terms of valuable human ends and that contrary to approaches that exclusively focus on income, expenditure and utility, places emphasis on functionings, capabilities and freedoms, and rights.

Sen (1990) understands functionings to relate to the things a person values doing or being. They are features of a person's state of existence ranging from relatively elementary states (e.g. being adequately nourished), to more complex personal states and activities (e.g. participation and appearing without shame). In contrast, he understands capabilities to relate to the ability of a person to achieve different combinations of valuable beings and doings that are within a person's reach, reflecting the opportunity or freedom to choose a life that a person values (see Clark, 2002). In his book 'Development as Freedom' (1999) Sen expands his capability framework integrating freedom and rights. ${ }^{6}$ These freedoms not only encompass political liberties, access to essential services and the reduction of deprivations, but also participation in market exchanges. The basic principle behind the capability approach is not to equalize the income of people and to reduce monetary inequality, but to equalize the capability each has to enjoy valuable activities and states of being. Therefore Sen advocates the promotion and expansion of valuable capabilities and equality in the space of basic capabilities, such as cross-national life expectancy, literacy and health care (Alkire, 2002).

Basically the first ${ }^{7}$ main operationalisation of Sen's capability approach was the Human Development Index (HDI) published in the Human Development Report (HDR) in 1990. The report defines human development as a process of enlarging people's choices, whereby the 'the most critical ones are to lead a long and healthy life, to be educated and to enjoy a decent standard of living. Additional choices include political freedom, guaranteed human rights and self-respect' (UNDP, 1990, p. 10). Nevertheless, the HDI has to be regarded as a pragmatic approach which avoids measuring levels of achievements (or functionings) as a measure of wellbeing because of the difficulties of doing so ${ }^{8}$. Instead it measures capabilities that enable one to achieve a set of functioning needed to improve or sustain a higher level of well-being. Therefore the HDI measures capabilities in terms of life expectancy, educational attainment and income. Since its introduction the HDI has been criticised ${ }^{9}$, and although it has been modified and improved since then, it is still considered as conceptually weak (Clark, 2002, ch. 1). 


\subsection{Subjective Well-being}

In the literature subjective well-being is a term used to encompass different subjective concepts or measures of the well-being, satisfaction or happiness of individuals. Diener et al. (2004) differentiate four concepts which in their view together constitute subjective well-being. These are negative affect, positive affect, domain satisfaction and cognitive life-satisfaction. This study will focus on the latter - the cognitive life-satisfaction - and will refer to it as subjective well-being for simplicity. Subjective well-being is defined as the subjective measurement of the overall satisfaction with life (see Camfield, 2003). In general it is assumed that individual satisfaction with life is a multidimensional concept. This multidimensional concept is believed to encompass not only material achievements but also other aspects of life, such as health, love, employment, and having children. Subjective well-being - when it is measured - refers to a person's declared well-being and is based on a person's answer to either a single question or a group of questions about his/her well-being (Rojas, 2003). Therefore subjective well-being can be regarded as an outcome measure by which to judge successful living (Diener and Suh, 2000).

Contrary to the monetary and capability approaches the subjective wellbeing concept makes it possible to avoid defining what welfare and wellbeing means. By using the answers to subjective questions, individuals define their level of welfare and well-being themselves (Ferrer-I-Carbonell, 2002). This can be seen as an advantage not only because it avoids value judgements about the constituent components of well-being (Kingdon and Knight, forthcoming), but also because there is no agreement on the final definition of the quality of life. Nevertheless it is still disputed whether a subjective well-being (or quality-of-life) approach can eventually avoid to define the essence of a good life (see for example Kajanoja, 2002; Michalos, 2003) and furthermore it is also disputed that there is something like an overall quality of life (Veenhoven, 2000).

However, if individuals define their level of welfare and well-being themselves, there are two main assumptions needed for a meaningful analysis of subjective questions. Firstly, that individuals are able to evaluate their own situation; and secondly, that responses among individuals can be compared (Ferrer-I-Carbonell, 2002). Veenhoven (2000) takes the position that individuals are able to evaluate their own situation. He argues that humans feel good or bad about particular things, whereby the mood level signals overall adaptation, which humans can reflect on. Furthermore he states that humans have an idea of how we have felt over the past (i.e. the last year). Critiques argue that subjective appraisals cannot be compared 
between persons since people 'have different scales in their mind'. It is believed that someone who reports to be 'very satisfied' may in fact be as happy as someone who reports to be 'satisfied' which is referred to in economics as the 'theorem of incomparable utilities' (Veenhoven, 2004, p. 20). This critique is generally answered with empirical findings. Diener and Lucas (1999) find that comparability within a given language community is given, and Ouweneel and Veenhoven (1991) review evidence from countries in which more than one language are spoken, showing that the subjective well-being scores across language groups are similar. Furthermore, Veenhoven (1991) finds - contrary to Easterlin - that life-satisfaction is not relative. A more challenging criticism of subjective well-being results from the so-called 'satisfaction paradox' (Zapf in Olson and Schober, 1993: 173). This satisfaction-paradox refers to the state of being satisfied despite objectively unsatisfactory living conditions. Sen $(1987,1992,1999)$ concludes that subjective well-being measures are unreliable (especially within the group of the poor) since poor people might adjust to and be satisfied with their living conditions, i.e. learn to be happy. Recent research, however, suggest that poor people do report lower global life satisfaction, but nevertheless report positive levels of satisfaction with life domains, especially in the area of social relationships (see Biwas-Diener and Diener, 2001).

In recent research it has been argued that quantitative approaches have to be complemented by a multidimensional view of poverty which is qualitative and includes the subjective assessment of poor people themselves (Hulme et al., 2001). Since the basic assumptions that individuals are able to evaluate their own situation and that their responses can be compared seem to be supported, subjective well-being measures are seen to have useful potential in multidimensional poverty measurements (see for example the conceptual framework of the Well-being in developing countries project set out in McGregor, 2004). As mentioned above, not all researchers share this view. In a recent working paper Clark and Qizilbash (2005) state that in their surveyed communities between $73 \%$ and $82 \%$ of respondents claimed to be either satisfied or very satisfied, despite large prevalent capability poverty. Therefore they doubt that 'data on satisfaction levels are, on their own, an adequate basis for evaluation the quality of life' (ibid: p. 26).

\section{THE CASE OF SOUTH AFRICA}

Having identified the three well-being/poverty measures used in this study, it is important to look more precisely at the South African circumstances to identify a possible level of analysis. 


\subsection{Poverty, Race and Ethnicity in South Africa}

During apartheid South Africa was dominated by the descendants of the white colonists whose material privilege was 'legitimated and consciously understood by them as an inevitable by-product of racial difference' (Lester et al., 2000, p. 3). Today South Africa's wealth and income is unevenly distributed among ethnic groups with Anglophone whites at the top followed by Afrikaners, Indians, Coloureds and Black Africans at the bottom. Du Toit (1998) reports an average income for whites in 1995 of around R103 per month compared to R71 for Indians, R32 for coloureds and R23 for Africans. Due to the apartheid system most of the poor people are to be found among the black Africans. The Project for Statistics on Living Standards and Development (PSLSD, 1994) states that $64.9 \%$ of all African people are poor (which are $94.7 \%$ of South Africa's population (RDP, 1995 ), whereas $32.6 \%$ of the coloureds ( $5 \%$ of the total population), $2.5 \%$ of the Indians $(0.1 \%$ of the total population) and just 0.5 of the whites are poor $(0.2 \%$ of the total population).

Although most of the poverty analyses regarding South Africa use race as a level of analysis, it is important to distinguish race from ethnicity. 'Races' are thought of as social groups with distinct physical features, such as South African whites, Africans, coloureds and Indians. In contrast, Zulus, Xhosas, Tswana and Afrikaners are considered ethnic groups because they have distinct languages and histories. Nevertheless, groups like the Nama were officially classified as Coloured but are a very distinct 'aboriginal' group. In South Africa the racial categorisation was officially constructed under the regime of apartheid. In the Population Registration Act (1950), the South African population was classified according to racial population groups: namely blacks, coloureds, Indians and whites, and within the racial groups according to ethnic or tribal labels (Henrard, 2002). That these were constructed and state imposed categories can be seen for example in the fact that in 1986, 1624 South Africans applied to be reclassified of whom 1102 were successful (Lester et al. 2000; Maré, 2001). On this foundation other laws were based which created race segregation along racial and ethnic lines in regard to residential areas, schooling, public services, etc. During the 1950s and 1960s the apartheid regime assigned separate residential areas called Bantustans and later 'homelands'. These were based on established language areas.

In regard to survey analysis it is important to understand that there are certain problems involved with the use of race as an analytical category. Stanfield (1993) describes these as the homogeneity and monolithic identity 
fallacies. The use of racial categorisations like blacks, coloureds, Indians and whites connote internal sameness, i.e. homogeneity with each race, which may not exist in practice. There is to my knowledge little literature in regard to macro studies of poverty (in the quantitative and especially economic tradition) in South Africa - except for the class analyses such as Seekings (2003), which tries to avoid the homogeneity fallacy by differentiating between the poverty levels using class. Another fallacy is the so-called monolithic identity problem. Some scholars ascribe certain characteristics to people of coloured origin and as a result ignore the range of identities (and therefore humanity) present in these groups. Both fallacies are to a certain extent overlapping since both races and individuals of these races are seen as uniform, but the homogeneity fallacy has to be seen as a macro-level phenomenon, whereas the monolithic identity fallacy is a micro-level phenomenon.

This study tries to avoid these fallacies and argues that it is important in the case of South Africa to identify distinct social groups on as detailed a level as possible. Research in the UK for example suggests that the South Asian minority population is not homogenous and therefore should be differentiated across religious sub-groups (Brown, 2000). Regarding South Africa it is suggested that the racial categorisation should be replaced by an ethnic categorisation along language groupings. In this study this is done by combining the variables race and language ${ }^{10}$. To a certain extent this sort of categorisation encompasses regional groups since certain languages are mainly spoken in certain areas ${ }^{11}$. Unfortunately information on religion and other aspects of identity are not available in the dataset, so no further breakdown is possible. Further classification could include gender, but this is for the sake of simplicity avoided here. Nevertheless, the advantages of a detailed differentiation of social groups emerge clearly using the present ethnic categorisation.

\subsection{Review of Well-being Studies Conducted in South Africa}

Researchers have generated a vast literature on well-being for South Africa stemming from the 1993 SALDRU dataset (PSLSD, 1994) on which this paper is based ${ }^{12}$. Klasen (1997) argues that poverty in South Africa has a strong racial dimension as a direct result of apartheid policies, with poverty being concentrated among the African population. In his study he constructs a composite well-being index (using the SALDRU, 1993 data) of 12 indicators, including income, health, education, household wealth, access to services, transport, and perceptions of quality of life and compares it to 
income and expenditure measures of poverty. He finds that the people who are defined poor by the constructed index only partly overlap with the expenditure poor. According to the comparison, Klasen identifies a total of 3.7 million severely deprived people who are not captured by the income poverty measure. Similar to the results published by the RDP (1995) his results show that $64 \%$ of the African people are poor, compared to $33 \%$ of coloured people, and 3\% of Indian people. The poverty rate of white people is close to zero in 1993.

Bookwalter and Dalenberg (2004) present a model of subjective wellbeing which they base upon poverty (including expenditure and capabilities) and household characteristics (such as housing, sanitation and transportation) partly adapted from Klasen (1997). They hypothesise that satisfaction depends upon various characteristics of the household. To test their hypothesis they construct an index ${ }^{13}$ with household factors which they then converted into a satisfaction measure using ordered probit regression techniques. The authors find that the ordered probit model correctly predicted $40.4 \%$ of the total observations, but varied significantly. It predicted best for the groups of satisfied (62\%) and dissatisfied (53\%), but predicted less well for the very dissatisfied $(27 \%)$, the very satisfied $(2 \%)$ and the neither satisfied nor dissatisfied $(0 \%)$. Further, Bookwalter and Dalenberg examined whether the results differ between rich and poor by computing an ordered probit model using the expenditure quintiles and their constructed index. They find that important differences exist among groups based upon expenditures, whereby transport and basic housing play the most important role for the poor, while sanitation, water, energy, education and health are relatively more important for the rich. The authors go on to conclude that 'self-reported subjective well-being is affected by a complex assortment of influences, of which basic economic factors play a role' (ibid: p. 346) and argue that their results have policy implications, since targets for policy are identified which affect well-being.

Kingdon and Knight (forthcoming) compare subjective well-being poverty with income and capabilities poverty and find that subjective well-being is related to both approaches. They conclude that income does not constitute an adequate measure of capability poverty, since they find variables (i.e. health, insecurity, mobility, etc.) which influence happiness, even after controlling for economic factors such as income and assets. Therefore they view subjective well-being as an encompassing concept. In a complex analysis using ordered probit models, they estimate several subjective well-being functions for South Africa and come up with a preferred equation which contains variables corresponding to the income approach, the basic needs 
approach, the relative functioning approach, and the security approach ${ }^{14}$. Observing differences between the South African racial groups, they argue that race itself is not associated with subjective well-being, but that 'unobserved circumstances which matter to happiness differ across the races' (ibid: p. 16), i.e. community factors such as public services and amenities.

What all these three studies regarding poverty and subjective well-being have in common is that they use race as a unit of analysis. While race is an imperfect unit of analysis, none of the studies discuss the problems of a racial classification. They do not explore differences inside the racial groups. Furthermore, the studies of Bookwalter and Dalenberg (2004) and Kingdon and Knight (forthcoming) identify causal relationships from their models, which their models cannot in fact prove. The first, for example, argues that subjective well-being is affected by certain influences and concludes that policies which target these influences could improve subjective well-being, implying a causal relationship. Nevertheless, it can only be inferred, not verified, that these influences have a causal effect on subjective well-being, since variables are simultaneously collected and it cannot even be shown that the independent variable(s) precedes the dependent variable (Bryman, 2001, p. 75). Since the models of Bookwalter and Dalenberg and Kingdon and Knight cannot establish this causal link between subjective well-being and certain influences, the conclusion that a policy change would result in an improvement of subjective well-being cannot hold up. It has not been shown that a change of the influences really results in higher subjective well-being. Although Kingdon and Knight state that they 'are unable convincingly to test the direction of causality' (ibid: p. 15), they generate a subjective wellbeing function. As it will be argued in the following pages, the ordered probit models are not suitable for the analysis of subjective well-being due to a number of questionable premises upon which this technique relies.

\section{METHODOLOGY}

\subsection{Dataset}

SALDRU collected information on 43,984 individuals in 8854 households, between September and December 1993, regarding education, health, fertility histories, consumption patterns, labour supply to the formal and informal sectors, migration and remittances, sources of income, and the perceived quality of life. The main purpose of the questionnaire was to focus on poverty using a mainly monetary approach, but the survey also tried to collect as much additional information as feasible. For this reason the main 
part of the survey is concentrated on household expenditure and income, while education, health, migration and perceived quality of life only play a minor role. Any study which is not primarily concerned with income and expenditure patterns has to deal with restricted available information (i.e. variables). For this study, the data was cleaned so that only those persons above the age of 16 and who answered the subjective well-being question with a valid value were included. Some observations with missing values on key variables were also removed. After the cleaning process, the survey yielded data on 7568 households. The data was weighted using the provided enumeration weight (see SALDRU, 1997).

\subsection{Creation of Categories}

4.2.1. Household expenditure. Poverty levels are usually measured using household expenditure since this measure is assumed to be more reliably reported and more stable than household income (Klasen, 1997). In the literature several reasons can be found why the use of income is problematic (e.g. Khandker, 2002, Coudouel et al., 2004). Firstly, people tend to forget what they may have earned over the asked period (week, month or year) or remember things they have earned earlier or later. In the case of the SALDRU questionnaire an individual is asked about the household income, so the possible errors are higher than if the individual had only been asked about his or her individual income. Secondly, people tend not to disclose the full extent of their income for several reasons. In the SALDRU-questionnaire it could especially be that the respondents do not know the exact income of other household members since the household sizes varied largely with a mean household size of $2.54^{15}$. A few households have over 40 members. Thirdly, some sources of income are difficult to observe, such as the extent to which the value of farm output is rising or falling over time.

For this study household expenditure is calculated as monthly per capita household expenditure by dividing the total household expenditure by the number of the household members. This derived variable is then divided into five categories: 0-100 Rand, 101-200 Rand, 201-300 Rand, 301-500 Rand, 501-1000 Rand, 1001-2000 Rand and 2001 Rand or higher ${ }^{16}$.

4.2.2. Capability indicators. There is an ongoing debate as to how to measure capabilities. In general variables regarding education, health and, sometimes, income are used as proxies for capability poverty. The principal aim for example of the UNDP in creating the HDI, the Capability Poverty Measure (CPM) or the Human Poverty Index (HPI) is that the goal of 
development should be to enable people to live long, well-informed and comfortable lives (see UNDP, 1990, 1996, 1997). But since the HDI (as well as the CPM and the HPI) represent measures which are meant mainly for cross-country comparison or the comparison of large homogeneous groups, indicating the relative position of a country/group relative to other countries/groups, they cannot be used to compare households (May et al., 2000) or individuals.

Since any construction of a capability index is not without problems, for this study three proxy variables are identified which are oriented on the UNDP's conceptual framework mentioned above. Health, the highest educational attainment, and income are used as indicators. Health is broken down into three categories, being healthy, being temporarily ill and having long-term illness. The highest educational attainment is grouped into five categories: 'no education', 'until junior certificate', 'until senior certificate', 'higher education', and 'university degree'. Lastly, total monthly per capita income is used, which is computed as the total monthly household income divided by the household size.

4.2.3. Subjective well-being. In the SALDRU questionnaire subjective well-being is based on a question regarding the perceived quality of life: 'Taking everything into account, how satisfied is this household with the way it lives these days'? The response options ranged from 'very satisfied' to 'very dissatisfied' (1-5). Since this question is addressing the household and not the individual's satisfaction, the first major assumption one might make is that this question is answered out of the individual's own personal satisfaction level and not that of the household as a whole. The question was asked of only one individual in each household and the individual is answering on behalf of the household. In this study it is assumed that the individual cognitively evaluates his or her well-being as a member of a certain household and therefore the answer to the satisfaction question can be regarded as the individual's subjective well-being. This assumption to regard it as personal subjective well-being might not be shared by quality-oflife proponents who could argue that this item should be rather seen as a domain satisfaction item.

4.2.4. Ethnicity. The variable which is referred to as 'ethnicity' in the following was created by combining two variables in the data set, namely 'race' and 'first language'. Contrary to existing analysis which uses 'race' as an independent variable, this study constructs a variable out of the four race groups and nine of the languages reported to be spoken as a first language. 
Most South African white respondents claimed to speak either Afrikaans or English as their language spoken at home and nearly all South African Indians claimed to speak English. Those few whites and Indians who did not speak either English or Afrikaans were classified as 'other languages' and due to their very small number they were excluded from the analysis. The coloured people either claimed to speak Afrikaans or English. In contrast the Africans claimed to speak English, Afrikaans, Zulu, Xhosa, Swazi, North Sotho, South Sotho, Tswana, Venda, Ndebele or Shangaan/Tsonga. Since there were only a small number of Blacks who principally speak English or Afrikaans, they were combined in one category. Therefore there are 15 ethnic categories in the newly created variable (see Table I for the ethnic breakdown of the sample).

\subsection{Data analysis Technique}

The responses to the subjective well-being question in the SALDRU questionnaire regarding household satisfaction belong to the class of qualitative or limited variables. Responses are discrete and ordered. In many studies they are therefore analysed using econometric techniques such as ordered probit or logit with individual effects (van Praag et al., 2003). The central idea is that 'underlying the ordered response is a latent, continuously distributed random variable' representing the propensity to be satisfied (see

TABLE I

Ethnic Groups in South Africa

\begin{tabular}{lrc}
\hline Ethnicity & $\%$ & $\%$ (cum.) \\
\hline Black Engl./Afrikaans & 0.4 & 0.4 \\
Xhosa & 16.5 & 16.9 \\
Zulu & 17.5 & 34.3 \\
Tswana & 9.5 & 43.9 \\
North Sotho & 11.0 & 54.9 \\
South Sotho & 7.6 & 62.5 \\
Venda & 1.4 & 63.8 \\
Shangaan/Tsonga & 4.8 & 68.6 \\
Swazi & 2.8 & 71.4 \\
Ndebele & 1.1 & 72.5 \\
Coloured Engl. & 1.8 & 74.4 \\
Coloured Afrikaans & 6.1 & 80.4 \\
Indian English & 2.7 & 83.2 \\
White English & 6.7 & 89.8 \\
White Afrikaans & 10.2 & 100.0 \\
\hline
\end{tabular}


Daykin and Moffat, 2002, p. 158). The ordered probit regression models a curvilinear relationship based on an inverse normal-distribution. It regresses a function of the probability that a case falls in a certain category of $\mathrm{Y}$, on a linear combination of $\mathrm{X}$ variables (Kohler and Kreuter, 2001). The coefficient $\beta$ (Beta) is computed following the maximum-likelihood principle. With these pre-defined assumptions about the distribution, the ordered probit model assumes the categories of the ordinal variable to fall in line, whereby they are not treated as independent. However this contradicts the nature of ordinal variables since ordinal variables can be rank ordered in categories, but the distance between the categories cannot be specified (de Vaus, 2002). Furthermore, the ordered probit model assumes causality can be represented by treating one variable as dependent and others as independent. It therefore assumes that the dependent variable is influenced by certain independent variables. In the case of subjective well-being it is assumed that subjective well-being can be explained with certain variables such as health, expenditure, etc., although it is impossible to establish causality through quantitative analysis. In contrast, by firstly using descriptive statistics and then using a multiple correspondence analysis (MCA) technique called HOMALS (available in SPSS 12), the limitations of the ordered probit model can be avoided.

HOMALS is mainly understood as an exploratory and descriptive technique. It is a model-free method that has few restrictions and assumptions. For example it is not based on distributional assumptions as the classical techniques are (i.e. regression or ordered probit). The only restriction is that HOMALS does not allow variables with negative value. Basically, in doing a MCA one analyses the relations between the categories of discrete variables in order to reveal the structure of a complex ordinal data matrix without the loss of essential information (Clausen, 1998). It does not try to confirm or reject hypotheses about underlying processes that generated the data (Blasius, 2002). Furthermore it presents the results visually in the form of graphical displays referred to as 'maps' which ease interpretation.

\section{RESULTS}

\subsection{Ethnicity and Poverty/Well-being}

In the following, in order to compare race and ethnicity as units of analysis, simple mean scores of per capita expenditure, per capita income and subjective well-being are computed. It is expected that a more detailed break-down of racial groups will reveal intra-racial differences in regard to poverty and well-being. However this is an empirical question. 
The mean scores of per capita income, expenditure and subjective wellbeing by race show the well-known racial differences in poverty or wellbeing. Whites have the highest average income and expenditure and report the highest average subjective well-being (see Table A.1). They are followed by the Indians, coloured people and lastly by the African population. In contrast, the mean scores of the ethnic groups show that apart from the assumed racial hierarchy there are also intra-racial differences in poverty and well-being. The white English speaking group have a higher income and expenditure than the White Afrikaans, the Coloured English speakers are better of than their Afrikaans speaking counterparts, and the black ethnic groups differ, too (see Table A.2). The black English/Afrikaans speakers have the highest mean income, the North Sotho speakers, the lowest. The per capita expenditure is highest among the Swazi and lowest among the Xhosa. Nevertheless, the mean subjective well-being is highest among the Venda and Ndebele and lowest among the South Sotho and Xhosa groups.

Converting the mean scores into rank scores gives the following total poverty or well-being hierarchy (see Table II). The racial hierarchy is still persistent, apart for one exception. Ranked by expenditure, income and subjective well-being rankings, the black English/Afrikaans speaking group ranks higher than the coloured Afrikaans speaking group. What is interesting in this ranking is that expenditure and income rankings are mainly the same, but the subjective well-being ranking is not. Although the white English speakers earn and spend more than the white Afrikaans speaking group, they report a lower mean subjective well-being. In contrast, among the coloured group, the English speakers who have a higher income and expenditure level claim to be more satisfied than the Afrikaans speakers. Among the black groups, there is no clear association between the income and expenditure and the subjective well-being rank.

The non-parametric Kruskal-Wallis Test shows that there are significant differences between the different racial and ethnic groups regarding their mean expenditure, income and subjective well-being level (see Table A.3 in appendix). Furthermore, there are significant differences between the black ethnic groups and between the coloured groups. The difference between the white ethnic groups is only significant for expenditure, income and education.

The comparison of poverty means has shown that there are racial differences but more importantly that there are significant intra-racial differences in expenditure, income, education and subjective well-being, which supports the argument that the racial groups are not homogenous groups. The concept of ethnicity introduced here shows that there are differences between the ethnic groups which are classified by race and language. It 
TABLE II

Poverty and Well-being Ranking by Ethnicity

\begin{tabular}{lccccc}
\hline & $\begin{array}{l}\text { Expenditure } \\
\text { rank }\end{array}$ & $\begin{array}{l}\text { Income } \\
\text { rank }\end{array}$ & $\begin{array}{l}\text { Education } \\
\text { rank }\end{array}$ & $\begin{array}{l}\text { Subjective } \\
\text { well-being rank }\end{array}$ & $\begin{array}{l}\text { Total } \\
\text { rank }\end{array}$ \\
\hline White English & 1 & 1 & 1 & 2 & 1 \\
White Afrikaans & 2 & 2 & 2 & 1 & 2 \\
Indian English & 3 & 3 & 3 & 3 & 3 \\
Coloured English & 4 & 4 & 4 & 4 & 4 \\
Black Engl./Afrikaans & 6 & 5 & 5 & 9 & 5 \\
Coloured Afrikaans & 8 & 7 & 6 & 7 & 6 \\
Venda & 10 & 10 & 7 & 5 & 7 \\
Tswana & 9 & 8 & 8 & 12 & 8 \\
Swazi & 5 & 6 & 13 & 13 & 9 \\
Shangaan/Tsonga & 7 & 9 & 15 & 8 & 10 \\
Ndebele & 12 & 12 & 14 & 6 & 11 \\
South Sotho & 11 & 11 & 10 & 15 & 13 \\
North Sotho & 14 & 15 & 9 & 10 & 14 \\
Zulu & 13 & 13 & 12 & 11 & 13 \\
Xhosa & 15 & 14 & 11 & 14 & \\
\hline
\end{tabular}

seems that ethnicity is a better unit of analysis than race. Furthermore, the analysis has found that the relationship between income or expenditure and subjective well-being seems to differ between the ethnic groups which will be explored further in the following analysis.

\subsection{Multiple Correspondence Analysis}

The HOMALS model is computed using per capita household expenditure, the proxy variables for capability poverty (education and health), subjective well-being and ethnicity. The analysis yielded a two-dimensional solution with eigenvalues ${ }^{17}$ of 0.413 on the first, and 0.260 on the second dimension (see Table A.4 in appendix). The eigenvalue of the first dimension is quite high since all the poverty and well-being indicators (except for health) and ethnicity are loading on this dimension, i.e. are associated with this dimension. Age $(0.005)^{18}$ and health status $(0.013)$ showed the weakest loading, whereas subjective well-being (0.379), highest educational qualification (0.552), total per capita expenditure, and ethnicity (0.766) had the strongest loading. Since subjective well-being, expenditure and education are associated with this first dimension, this dimension could be interpreted as a poverty or well-being dimension. The further a group is to the right side of the scale (positive values) the better off the person is in 
terms of poverty or well-being. Clearly, as a legacy of apartheid, the different racial as well as ethnic groups differ on this dimension, i.e. in their level of poverty or well-being. The findings of 5.1 are supported since the hierarchy on this dimension is equal to the mean scores of the different ethnic groups.

The smaller eigenvalue of the second dimension is due to the fact that although four variables (expenditure, education, ethnicity and age) are associated with this dimension, all do not load very strongly. Interestingly age $(0.005)$ was not associated with the poverty or well-being dimension (dimension 1) but is now associated with the second dimension whereas subjective well-being was associated with the first dimension but is not associated with the second dimension (0.042). As with dimension one, health again is not related $(0.031)$ with the second dimension, whereas ethnicity (0.322) and expenditure (0.431) are associated, although less strong as with dimension 1 (Table A.4).

The graphical mapping of the poverty measures and the ethnic groups depict the findings. Dimension one is a poverty or well-being dimension ${ }^{19}$ and on this dimension, we can see that all black groups are situated on the left spectrum which are close to low expenditure, high capability poverty (in regard of ill-health and low education) and low subjective well-being, whereas both white groups are situated on the right end close to high expenditure, low capability poverty (good health and good education) and high subjective well-being.

Dimension two is equivalent to the individual variation inside the ethnic groups and is much more difficult to interpret. The question is to how this difference between the ethnic groups can be explained. By looking closely at the distribution of ethnic groups along the second dimension one can see that age and education appear to be important factors apart from expenditure which are responsible for intra-ethnic variation. This intra-ethnic variation must be further investigated to be sure about the underlying structure. One possible interpretation of the importance of expenditure, age and education is that in South African households are often dependent on a single earner, i.e. someone who is in employment (see Seekings, 2003), and as Ferreira and Litchfield (in van der Berg, 2002) argue, the chances of having employment is higher, the higher the education is a person holds. Van der Berg (2002) argues not only education but the quality of education (apart from location factors) ${ }^{20}$ is important. But naturally education is more important for the younger generation, therefore the age structure of the ethnic groups is important, too. The results of the HOMALS model point in the direction that for the younger 


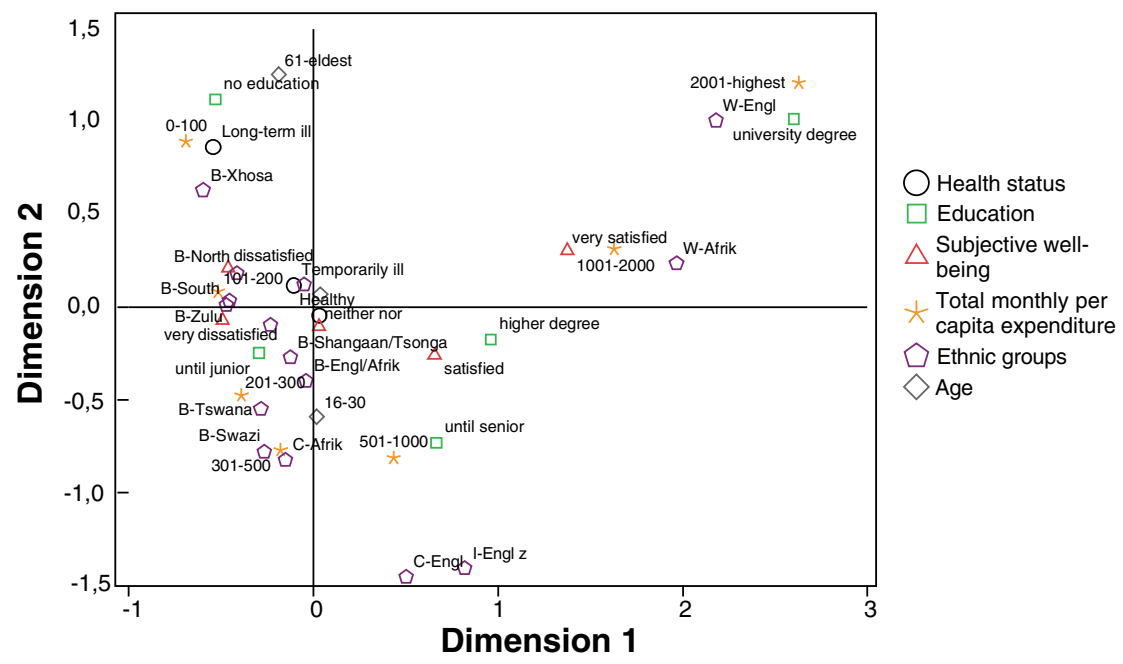

Fig. 1. Multiple correspondence analysis (HOMALS).

generation education is important in order to enhance chances on the labour market, but since the labour market prospects differ significantly between the nine provinces, location plays a big role. So educated individuals of black ethnic groups close to the economic centres (Gauteng and the Western Cape) have higher chances of upward mobility since there are more jobs available. On the other hand, as van der Berg points out, the quality of education varies significantly between and inside the provinces. As Moll (2000) states, South Africa has experienced a decrease in interracial earning inequality during the years $1980-1993$ but an increase in inequality within the race groups. He explains that the end of apartheid resulted in the removal of labour market discrimination which gave some African the opportunity of upward mobility. Meanwhile, former privileged uneducated whites lost their apartheid protection. Education therefore became the factor which determined who could benefit from the new opportunities or who lost his job security.

\section{DISCUSSION}

This paper has introduced ethnicity as a concept of analysis. The descriptive analysis has shown that race as a unit of analysis is hiding intra-racial differences. By using ethnicity as a unit of analysis, constructed from a 
combination of established race classifications and the language spoken at home, intra-racial differences in expenditure poverty, capability poverty and subjective well-being are revealed. Ethnicity therefore seems to be a worthwhile unit of analysis for future research regarding poverty and inequality. Although ethnicity seems to be a better unit of analysis it is by no means perfect. Further aspects like gender, location or age could be integrated, if the sample size is larger.

Furthermore, this study has introduced an alternative multivariate technique for the analysis of categorical data, which, as it is argued, is not dependent on assumptions such as causality and therefore has an advantage over more widely used multivariate techniques such as ordered probit regressions. The multi correspondence analysis - in this study HOMALS helped to identify underlying structures independent of causalities. A two dimensional HOMALS model suggested that in the case of South Africa there is a well-being hierarchy due to the apartheid past which is based on race and ethnicity. More interestingly it has further uncovered a complex connection between education, age and location which is responsible for the individual variation within the ethnic groups. Nevertheless, further research is needed to uncover this complex structure.

Finally, in regard of subjective well-being it was found that there is no clear association between income or expenditure and subjective well-being of the African ethnic groups. As reported earlier, the models of Bookwalter and Dalenberg (2004) do not predict subjective well-being very well for the very dissatisfied $(23.3 \%$ of the sample) and the very satisfied $(7.9 \%$ of the sample). Interestingly, $89.4 \%$ of the very dissatisfied are from African ethnic groups, whereas of the very satisfied, $41.2 \%$ are from African ethnic groups and $47.3 \%$ are from white ethnic groups. Regarding these facts and the mean rank scores for income, expenditure and subjective well-being it seems that to a certain extent there are cultural differences between the ethnic groups which are associated with the subjective well-being levels. The question why the equation cannot explain the subjective well-being level of the very dissatisfied Africans has two possible answers. It could be, firstly, that further proxy variables need to be integrate into their model to explain the difference between the dissatisfied and the very dissatisfied, or, secondly, that there are certain cultural differences between the races and ethnic groups which are not considered. The question why the white English speaking group does not have the highest mean subjective well-being level could have two possible explanations. Firstly, clearly the white population has lost their state protection with the end of apartheid. Maybe the loss of apartheid protection was perceived as more severe among the English 
speaking elites compared to the Afrikaans speaking population. The Afrikaans speaking white population could have in general been less affected due to laws like the sunset clause which granted civil servants their jobs after the transition from apartheid to democracy. This could have resulted in larger pessimism and lower perceived satisfaction among the group of the English speaking whites and in comparison larger optimism among the Afrikaans speaking whites. A second explanation might be that the returns to a high income or expenditure in regard of subjective well-being are diminishing after a certain level. What the HOMALS model further suggests is that subjective well-being indeed seems to be an outcome measure since it is only associated with the first well-being dimension and does not have a significant individual variation (i.e. was associated with dimension two). But to understand this outcome of subjective well-being more research is needed into the complex structure in South Africa, partly uncovered in this paper.

\section{NOTES}

${ }^{1}$ South Africa is reported to have a mean life satisfaction of 6.73 (on a scale from $0-10$ ) which ranks it on place 25 out of 42 countries (Schyns, 2002).

${ }^{2}$ Klasen (2002) states a Gini coefficient of 0.60 and argues that it is among the highest in the world.

${ }^{3}$ The South African Human Development Report suggests that inequality has persisted and increased slightly since the end of apartheid.

${ }^{4}$ Conducted by the Project for Statistics on Living Standards and Development (PSLSD) of the Southern African Labour and Development Research Unit (SALDRU) at the University of Cape Town.

${ }^{5}$ In the following well-being and poverty are boldly used interchangeably, although the author acknowledges the differences between poverty and well-being and is aware of the problems of using poverty and well-being interchangeably.

${ }^{6}$ In a recent paper Sen (2005) argues that although human capabilities and rights go well with each other (i.e. that many human rights can be regarded as right so certain capabilities) the capability framework does not encompass the human rights approach in the sense that human rights cannot be 'adequately analysed within the capability framework' (ibid: p. 163).

${ }_{7}$ Sen himself (for example in 1985) operationalised human capabilities in earlier works.

${ }^{8}$ Although the income component of the HDI is often regarded as a proxy for functionings.

${ }^{9}$ A first critique is that the HDI is applied to rank countries and therefore does not represent a poverty definition or measurement in the strict sense (which would focus on individuals or households) (see Boltvinik, 1998). Secondly, the process of aggregation is criticised, because capabilities are regarded as incommensurable, and therefore should be presented separately for each capability. In general aggregation is further criticised because it conceals information (Ruggeri Laderchi et al., 2003). Thirdly, it is argued that the attached weights to the three indicators are arbitrary, and that the explanatory power of the index is limited to how well a certain country is doing in relation to other countries. Fourthly, it is criticised that since the 
HDI represents an average, it excludes information on inequality, gender or urban and rural people (Clark, 2002, ch. 1).

${ }_{10}$ There are 11 official languages in South Africa.

${ }^{11}$ The Black English or Afrikaans speakers are to be found in all provinces (between 7 and $16.5 \%$ ) except for Northern Transvaal and the North West Province but the majority are situated in Western Cape (28.9\%). The Xhosa speakers live mainly in the Eastern Cape, the group of Zulus mainly in KwaZulu Natal, the Tswana in the North West, the South Sotho in the Free State, the Venda, Swazi and Ndebelele in Mpumalanga, the North Sotho and the Shangaan/Tsonga in Limpopo, the Coloured English and Coloured English in Western Cape, the Indian English in KwaZulu Natal, the White English in the Western Cape, Gauteng. and the Eastern Cape, the White Afrikaans mainly in Gauteng and Western Cape.

12 There are now many relevant poverty and well/being datasets since the SALDRU survey, e.g. the Census and October Household Surveys, the Labour Force Survey, etc. but the SALDRU survey is still extensively used although it is increasingly dated. Nevertheless it still represents the only living standards measurement study in South Africa.

${ }_{13}$ The index is estimated as follows ( $i b i d 2004$, p. 339): $I i=b 1+b 2 \operatorname{EDUC} i+b 3 \operatorname{EXPEND} i+$ $b 4$ DURABLES $i+b 5$ ILLNESS Dummy $i+\delta j$ HOUSING Dummies $i+\theta j$ WATER SOURCE Dummiesi $+\lambda j$ SANITATION Dummiesi $+\pi j$ COOKING ENERGY Dummiesi $+\alpha j$ TRANSPORTATION Dummiesi $+e i$.

${ }^{14}$ The security approach refers to the physical and economical risks of households. Kingdon and Knight (forthcoming) identify exposure to crime, debt, the risk of unemployment and the lack of assets.

15 and a standard deviation of 2.97 .

${ }^{16}$ In contrast to the procedure suggested by the World Bank this was not done with the help of an adult equivalent scale.

${ }^{17}$ Eigenvalues are squared correlations

18 These factors are discrimination measures and vary from 0 to 1 .

${ }^{19}$ Dimension one is equivalent to the mean ranks of the ethnic groups regarding poverty and well-being measures.

${ }^{20}$ Indeed, in a separate HOMALS analysis, location was controlled for and the variable province (the nine provinces) had the strongest factor loading on dimension two.

\section{APPENDIX}

TABLE A.1

Mean Scores by Race Groups

\begin{tabular}{lrrlrr}
\hline & Expenditure & Income & $\begin{array}{l}\text { Subjective } \\
\text { well-being }\end{array}$ & $\begin{array}{l}\text { Education } \\
\text { in years }\end{array}$ & Age \\
\hline African & 287.9563 & 300.9492 & 2.3060 & 4.4923 & 38.86 \\
Coloured & 449.6201 & 526.4558 & 2.9226 & 5.8769 & 40.18 \\
Indian & 797.8656 & 992.0418 & 3.3645 & 8.0749 & 37.30 \\
White & 1683.6769 & 2294.9727 & 3.7543 & 10.0121 & 42.90 \\
Total Mean & 547.2816 & 652.7683 & 2.6273 & 5.6284 & 39.60 \\
\hline
\end{tabular}

Subjective well-being scale $1-5,1=$ very dissatisfied, $5=$ very satisfied. 
TABLE A.2

Mean Scores by Ethnicity

\begin{tabular}{lrrrrr}
\hline & Expenditure & Income & $\begin{array}{l}\text { Subjective } \\
\text { well-being }\end{array}$ & $\begin{array}{l}\text { Education } \\
\text { in years }\end{array}$ & Age \\
\hline Black English/Afrikaans & 435.5028 & 540.1224 & 2.5479 & 6.0272 & 36.51 \\
Xhosa & 236.7085 & 257.4189 & 2.1245 & 4.3579 & 41.24 \\
Zulu & 270.4450 & 258.9405 & 2.3456 & 4.3065 & 40.41 \\
Tswana & 353.2832 & 394.9417 & 2.3085 & 5.0405 & 37.25 \\
North Sotho & 244.5931 & 253.8328 & 2.3483 & 4.6121 & 37.15 \\
South Sotho & 286.6877 & 310.9096 & 2.0822 & 4.3926 & 38.48 \\
Venda & 323.3250 & 336.6107 & 2.9373 & 5.6292 & 39.26 \\
Shangaan/Tsonga & 390.9222 & 365.9804 & 2.7671 & 4.1607 & 35.43 \\
Swazi & 445.9285 & 499.7827 & 2.1935 & 4.3041 & 34.15 \\
Ndebele & 272.0307 & 299.1785 & 2.9055 & 4.2165 & 39.24 \\
Coloured English & 701.5669 & 851.4079 & 3.1763 & 7.3536 & 40.60 \\
Coloured Afrikaans & 372.4872 & 434.3130 & 2.8465 & 5.4333 & 40.05 \\
Indian English & 797.8656 & 992.0418 & 3.3645 & 8.0749 & 37.30 \\
White English & 1807.0038 & 2327.3456 & 3.6814 & 10.1864 & 45.01 \\
White Afrikaans & 1602.8676 & 2275.6900 & 3.8022 & 9.8974 & 41.52 \\
Total Mean & 547.2816 & 652.7683 & 2.6273 & 5.6284 & 39.60 \\
\hline
\end{tabular}

TABLE A.3

Kruskall-Wallis Non-parametric Test

\begin{tabular}{lrrrrr}
\hline & $\begin{array}{l}\text { Expenditure } \\
\text { Chi-square }\end{array}$ & $\begin{array}{l}\text { Income } \\
\text { Chi-square }\end{array}$ & $\begin{array}{l}\text { Education } \\
\text { Chi-square }\end{array}$ & $\begin{array}{l}\text { Subjective well-being } \\
\text { Chi-square }\end{array}$ & df \\
\hline Blacks & $324.77^{* * * *}$ & $255.12^{* * * *}$ & $37.88^{* * *}$ & $119.05^{* * *}$ & 9 \\
Coloureds & $96.06^{* * *}$ & $62.69^{* * *}$ & $46.54^{* * *}$ & $7.30^{* * *}$ & 1 \\
Whites & $18.17^{* * *}$ & $5.32^{* * * *}$ & $3.49^{* *}$ & 2.71 & 1 \\
All ethnicity groups & $1156.03^{* * *}$ & $2562.73^{* * *}$ & $1562.10^{* * *}$ & $1281.87^{* * *}$ & 14 \\
Race groups & $2980.70^{* * *}$ & $2689.25^{* * *}$ & $2330.90^{* * *}$ & $1156.03^{* * *}$ & 3 \\
\hline
\end{tabular}

$* * *$ significant on $1 \%$-level, **significant on $5 \%$-level 
TABLE A.4

Multiple Correspondence Analysis - HOMALS model summary

\begin{tabular}{lll}
\hline & Dimension 1 & Dimension 2 \\
\hline Eigenvalues & 0.413 & 0.260 \\
Subjective well-being & 0.379 & 0.042 \\
Expenditure & 0.762 & 0.431 \\
Ethnicity & 0.766 & 0.322 \\
Education & 0.552 & 0.412 \\
Health & 0.013 & 0.031 \\
Age & 0.005 & 0.319 \\
\hline
\end{tabular}

TABLE A. 5

Multiple Correspondence Analysis - HOMALS Model

\begin{tabular}{lclc}
\hline Ethnicity & Dimension 1 & Ethnicity & Dimension 2 \\
\hline Xhosa & -0.597 & Coloured English & -1.454 \\
North Sotho & -0.412 & Indian English & -1.408 \\
South Sotho & -0.470 & Coloured Afrikaans & -0.823 \\
Zulu & -0.455 & Black Swazi & -0.779 \\
Ndebele & -0.230 & Black Tswana & -0.550 \\
Tswana & -0.283 & Black Afrikans/English & -0.398 \\
Swazi & -0.264 & Black Shangaan & -0.271 \\
Shangaan/Tsonga & -0.125 & Black Ndebele & -0.095 \\
Venda & -0.050 & Black South & 0.012 \\
Coloured Afrikaans & -0.38 & Black Zulu & 0.034 \\
Black Afrikaans/English & 0.503 & Black Venda & 0.122 \\
Coloured English & 0.842 & Black North & 0.183 \\
Indian English & 0.819 & White Afrikaans & 0.236 \\
White Afrikaans & 1.967 & Black Xhosa & 0.630 \\
White English & 2.181 & White English & 1.006 \\
2001-highest & 2.260 & 301-500 & 1.069 \\
1001-2000 & 1.639 & $501-1000$ & 0.978 \\
501-1000 & 0.676 & 201-300 & 0.445 \\
301-500 & 0.003 & 101-200 & -0.134 \\
201-300 & -0.382 & 1001-2000 & -0.545 \\
101-200 & -0.611 & $0-100$ & -0.933 \\
0-100 & -0.794 & 2001-highest & -1.546 \\
Very satisfied & 1.375 & Very satisfied & 0.305 \\
Satisfied & 0.656 & Dissatisfied & 0.211 \\
Neither & 0.030 & Very dissatisfied & -0.072 \\
Dissatisfied & -0.459 & Neither & -0.105 \\
Very dissatisfied & -0.490 & Satisfied & -0.260 \\
Healthy & 0.032 & Healthy & -0.045 \\
Temporarily ill & -0.106 & Temporarily ill & 0.117 \\
\hline & & &
\end{tabular}


TABLE A.5

Continued

\begin{tabular}{lclc}
\hline Ethnicity & Dimension 1 & Ethnicity & Dimension 2 \\
\hline Long-term ill & -0.542 & Long-term ill & 0.863 \\
No education & -0.529 & Until Senior C. & -0.731 \\
Until Junior C. & -0.293 & Until Junior C. & -0.248 \\
Until Senior C. & 0.667 & Higher Education & -174 \\
Higher education & 0.961 & University Degree & 1.013 \\
University degree & 2.602 & No education & 1.120 \\
31-60 years & 0.037 & 16-30 years & -0.590 \\
16-30 years & 0.019 & 31-60 years & 0.069 \\
61-eldest & -0.186 & 61-eldest & 1.254 \\
\hline
\end{tabular}

\section{REFERENCES}

Aliber, M.: 2003, 'Chronic poverty in South Africa: Incidence, causes and policies'. World Development 31, pp. 473-490.

Alkire, S.: 2002, Valuing Freedoms. Sen's Capability Approach and Poverty Reduction (Oxford University Press, Oxford).

Blackwood, D. and R. Lynch: 1993, 'The measurement of inequality and poverty: A policy maker's guide to the literature'. World Development 22, pp. 567-578.

Blasius, J.: 2002, Korrespondenzanalyse (Oldenburg, München).

Biwas-Diener, R. and E. Diener: 2001, 'Making the best of a bad situation: Satisfaction in the slums of Calcutta'. Social Indicators Research 55, pp. 329-352.

Boltvinik, J.: 1998, Poverty Measurement Methods, Poverty Reduction Series, UNDP/SEPEP, http://www.undp.org/poverty/publications/pov_red/Poverty_Measurement_Methods.pdf.

Bookwalter, J. and D. Dalenberg: 2004, 'Subjective well-being and household factors in South Africa'. Social Indicators Research 65, pp. 333-353.

Brown, M.: 2000, 'Religion and economic activity in the South Asian population'. Ethnic and Racial Studies 23, pp. 1035-1061.

Bryman, A.: 2001, Social Research Methods (Oxford University Press, Oxford).

Camfield, L.: 2003, Using Subjective Measures of Well-being in Developing Countries, Unpublished Working Paper, ESRC Research Group on Well-being in Developing Countries, University of Bath.

Carter, M. and J. May: 1999, 'Poverty, livelihood and class in rural South Africa'. World Development 27, pp. 1-20.

Clark, D.: 2002, Visions of Development. A Study of Human Values (Edward Elgar, Cheltenham).

Clark, D. and D. Hulme: 2005, Towards A Unified Framework for Understanding the Depth, Breadth and Duration of Poverty. Global Poverty Research Group Working Paper Series, GPRG-WPS-020, University of Manchester and Oxford.

Clark, D. and M.Qizilbash: 2005, Core Poverty, Basic Capabilities and Vagueness: An Application to the South African Context. Global Poverty Research Group Working Paper, University of Manchester and Oxford.

Clausen, S.E.: 1998, Applied Correspondence Analysis. An Introduction, Series: Quantitative Applications in the Social Sciences (Sage, London).

Coudouel, A., J. Hentschel and Q. Wodon: 2004, Poverty Measurement and Analysis, in PRSP Sourcebook: Core Techniques and Cross Cutting Issues, Volume 1:1-48, http://povlibrary.worldbank.org/files/5467_chap1.pdf. 
CPRC: 2004, The Chronic Poverty Report 2004-05, Chronic Poverty Research Centre, Institute for Development Policy and Management, University of Manchester.

Daykin, A. and P. Moffat: 2002, 'Analyzing ordered responses: A review of the ordered probit model'. Understanding Statistics 1, pp. 157-166.

de Vaus, D.: 2002, Surveys in Social Research 5th ed. (Routledge, London).

Diener, E. and R.E. Lucas: 1999, 'Personality, and subjective well-being', in D. Kahneman, E. Diener and N. Schwarz (eds.), Well-being: The foundations of hedonic psychology, (Russel Sage Foundation, New York), pp. 213-229.

Diener, E. and E.M. Suh: 2000, 'Measuring subjective well-being to compare the quality of life', in E. Diner and E.M. Suh (eds.), Culture and Subjective Well-being, (MIT Press, Cambridge), pp. $1-12$.

Diener, E., C. Scollon and R. Lucas: 2004, 'The evolving concept of subjective well-being: The multifaceted nature of happiness'. Advances in Cell Aging and Gerontology 15, pp. $187-219$.

Du Toit, J.: 1998, The Structure of the South African Economy, Southern Books 2 ed. (Halfway House, Johannesburg).

Ferrer-I-Carbonell, A.: 2002, Subjective Questions to Measure Welfare and Well-being, Discussion Paper (Tinbergen Institute, Amsterdam).

Glaser, D.: 2001, Politics and Society in South Africa: a critical introduction (Sage, London).

Henrard, K.: 2002, 'Post apartheid south africa's democratic transformation process: Redress of the past, reconciliation and "unity in diversity". The Global Review of Ethnopolitics 1, pp. $18-38$.

Hulme, D. and A. Shepherd: 2003, 'Conceptualizing chronic poverty'. World Development 31(3): pp. 403-423.

Hulme, D., K. Moore and A. Shepherd: 2001, Chronic poverty: Meanings and analytical frameworks, Chronic Poverty Research Centre, Working Paper 2, Institute for Development Policy and Management, University of Manchester.

Jesuit, D. and T. Smeeding: 2002, Poverty Levels in the Developed World, Luxembourg Income Study Working Papers No. 321 (Syracuse University, New York).

Kajanoja, J.: 2002, 'Theoretical bases for the measurement of quality of life', in E. Gullone and R. Cummins (eds.), The Universality of Subjective Well-being Indicators. A Multi-disciplinary and Multi-national Perspective, Social Indicators Research Book Series, 16 (Kluwer Academic Publishers, Dordrecht), pp. 63-80.

Khandker, S.: 2002, Poverty manual (World Bank, Washington), http://web.worldbank. org/WBSITE/EXTERNAL/WBI/WBIPROGRAMS/PGLP/0, contentMDK:20284296 menuPK: 461269 pagePK:64156158 piPK:64152884 theSitePK:461246,00.html.

Kingdon, G. and J. Knight (2006), 'Well-being poverty versus income poverty and capabilities poverty?' Journal of Development Studies, forthcoming.

Klasen, S.: 1997, 'Poverty, inequality and deprivation in South Africa: An analysis of the 1993 SALDRU survey'. Social Indicators Research 41, pp. 51-94.

Klasen, S.: 2002, 'Social economic, and environmental limits for the newly enfranchised in South Africa?'. Economic Development and Cultural Change 50, pp. 607-42.

Kohler, U. and F. Kreuter: 2001, Datenanalyse mit Stata: allgemeine Konzepte der Datenanalyse und ihre praktische Anwendung (Wissenschaftsverlag, München).

Lester, A., E. Nel and T. Binns: 2000, South Africa. Past Present and Future. Gold at the End of the Rainbow? (Person Education Limited, London).

Maré, G.: 2001, 'Race counts in contemporary South Africa: 'An illusion of ordinariness'. Transformation 47, pp. 75-93.

May, J., I. Woolard and S. Klasen: 2000, 'The nature and measurement of poverty and inequality', in J. May (ed.), Poverty and Inequality in South Africa: Meeting the Challenge, (Zed Books, London), pp. 19-50. 
McGregor, J.A.: 2004, Researching Well-being: Communicating between the Needs of Policy Makers and the Needs of People, Paper for the International Workshop on Researching Well-being in Developing Countries, Hanse Institut for Advanced Studies, Bremen.

Michalos, A.: 2003, Observations on Key National Performance Indicators. Mimeographed (University of Northern British Columbia, Prince George, Canada).

Moll, P.: 2000, 'Discrimination is declining in South Africa but inequality is not'. Journal of Studies in Economics and Econometrics 24, pp. 91-108.

Møller, V.: 1997, 'South Africa's emergent "social indicators movement"'. Social Indicators Research 41, pp. 1-14.

Olson, G. and B. Schober: 1993, 'The satisfied poor. Development of an intervention-oriented theoretical framework to explain satisfaction with a life in poverty'. Social Indicators Research 28, pp. 173-193.

Ouweneel, P. and R. Veenhoven: 1991, 'Cross-national differences in happiness: Cultural bias or societal quality?', in N. Bleichrodt and P. Drenth (eds.), Contemporary Issues in Crosscultural Psychology (Swets and Zeitlinger, Amsterdam), pp. 168-184.

PSLSD (1994), South Africans Rich and Poor: Baseline Statistics Southern Africa Labour and Development Research Unit, Cape Town.

RDP Office: 1995, Key Indicators of Poverty in South Africa (RDP Office, Pretoria).

Rojas, M.: 2003, The Multidimensionality of Poverty: A Subjective Well-Being Approach (WIDER Conference Paper, Helsinki).

Ross, R.: 1999, A Concise History of South Africa (Cambridge University Press, Cambridge).

Ruggeri Laderchi, C., R. Saith and F. Stewart: 2003, 'Does it matter that we do not agree on the definition of poverty? A Comparison of Four Approaches'. Oxford Development Studies 31, pp. 243-274.

SAHDR: 2003. South Africa Human Development Report 2003. The Challenge of Sustainable Development: Unlocking People's Creativity, UNDP South Africa, Oxford University Press, New York.

SALDRU: 1997, Overview, http://www.worldbank.org/html/prdph/lsms/country/za94/docs/ za94ovr.txt.

Schyns, P.: 2002, 'Wealth of nations, individual income and life satisfaction in 42 countries: A multilevel approach'. Social Indicators Research 60, pp. 5-40.

Seekings, J.: 2003, Social Stratification and Inequality in South Africa at the End of Apartheid, Working Paper 31, Centre for Social Science Research, University of Cape Town.

Sen, A.: 1981, Poverty and Famines. An Essay on Entitlement and Deprivation (Clarendon Press, Oxford).

Sen, A.: 1985, Commodities and Capabilities (Oxford University Press, Oxford).

Sen, A.: 1987, On Ethics and Economics (Blackwell, Oxford).

Sen, A.: 1990, 'Development as capability expansion', in K. Griffin and J. Knight (eds.), Human Development and the International Development Strategy for the 1990s (Macmillan, London), pp. 41-58.

Sen, A.: 1992, Inequality Re-examined (Oxford University Press, Oxford).

Sen, A.: 1999, Development as Freedom (Oxford University Press, Oxford).

Sen, A.: 2005, 'Human rights and capabilities'. Journal of Human Development 6, pp. 151-166.

Stanfield, J.H.: 1993, Race and Ethnicity in Research Methods (Sage, London).

UNDP: 1990, Human Development Report 1990, Concept and Measurement of Human Development (Oxford University Press, New York).

UNDP: 1996, Human Development Report 1996, Economic Growth and Human Development (Oxford University Press, New York).

UNDP: 1997, Human Development Report 1997, Human Development to Eradicate Poverty (Oxford University Press, New York). 
van der Berg, S.: 2002, Education, Poverty and Inequality in South Africa, Paper to the Conference of the Centre for the Study of African Economies Economic growth and poverty in Africa, Oxford, pp. 1-26.

van Praag, B., P. Frijters and A. Ferrer-I-Carbonell: 2003, 'The anatomy of subjective wellbeing'. Journal of Economic Behavior \& Organization 51, pp. 29-49.

Veenhoven, R.: 1991, 'Is happiness relative?'. Social Indicators Research 24, pp. 1-34.

Veenhoven, R.: 2000, 'The four qualities of life: ordering concepts and measures of the good life'. Journal of Happiness Studies 1, pp. 1-39.

Veenhoven, R.: 2004, Subjective Measures of Well-being, Discussion Paper No. 2004/07 (World Institute for Development Economics Research, United Nations University, Helsinki).

Wagle, U.: 2002, 'Rethinking poverty: Definition and measurement'. International Social Science Journal 54, pp. 155-165.

World Bank: 2005, South Africa Country Brief, http://web.worldbank.org/WBSITE/ EXTERNAL/COUNTRIES/AFRICAEXT/SOUTHAFRICAEXTN/0,menuPK:368086 PagePK:141132 piPK:141107 theSitePK:368057,00.html.

Centre for Census and Survey Research and

Institute for Development Policy and Management

University of Manchester

2nd floor, Booth Street East,

M13 9PL

Manchester, $U K$

E-mail: daniel.neff@postgrad.man.ac.uk 